\title{
De redelijkheid van de christelijke theologie
}

\begin{abstract}
The reasonableness of Christian theology

For many years Vincent Brümmer (* 1932) was the youngest professor in the theological faculty of the University of Utrecht (1967-97). His was not only a boyish style, but he also reformed profoundly the philosophical training in the department of philosophy of religion and ethics. His analytical approach to philosophy of religion influenced very much doing philosophy of religion in The Netherlands and abroad, but we have not only questions of meaning, but also issues of truth. The history of religion and theology, of culture and society, of the sciences and the humanities between the century of the New Testament and about 1800 show immense influences elicited by the Christian faith. There is also the history of the philosophia Christiana pointing out that the best possible Person must exist and that the best possible Person acts in the best possible way by coming into his world as God incarnate. We know who He is, because only Jesus cracked the reality of the life and thinking of the archaic and ancient religions and philosophies.
\end{abstract}

\section{VINCENTIUS OCTOGENARIUS}

Het is wennen. Vele, vele jaren was Vincent Brümmer - ik blijf de Umlaut eren - de jongste hoogleraar van de theologische faculteit van de Universiteit Utrecht. Ik heb het altijd betreurd, dat hij op zijn $65^{\text {ste }}$ met emeritaat moest gaan. Als de oude traditie dat een hoogleraar op zijn $70^{\text {ste }}$ emeritus werd, in 1997 gegolden had, zou Vincents leven er nog transparanter hebben uitgezien: 35 jaar vóór Utrecht en 35 jaar als hoogleraar in de godsdienstwijsbegeerte in Utrecht. Ik durf ook te stellen, dat als Vincent Brümmer in 2002 - en niet in 1997 - met emeritaat gegaan was, de geschiedenis van Utrechts theologische faculteit en die van de Nederlandse Kerk geheel anders verlopen zouden zijn. Dan zou kerkelijk Nederland veel gelukkiger geweest zijn en zou Theologie Utrecht nog bestaan hebben. Nu is hij octogenarius.

Op 30 juni 2012 overleed plotseling tot grote ontsteltenis van allen die hem omringden, mijn grootse leermeester Bertus de Rijk (* 1924). In 2013 zouden we elkaar 50 jaar gekend hebben. In het jaar van Vincentius octogenarius kennen Vincent en Jean Brümmer en ik elkaar 45 jaar. In 1966 werd Vincent benoemd tot de opvolger van Loen (1955-66) - christenwijsgeer bij de gratie Gods. ${ }^{1}$ Hervormd Nederland had dat niet verwacht en ik haastte mij om Vincents proefschrift over Dooyeweerd te gaan bestuderen. Begin januari 1967 kwamen de Brümmers naar Nederland.

Na een paar weken vroeg ik als laatste student van Loen bij Prof. Brümmer een gesprek aan. Het werd het begin van honderden gesprekken. Er waren half januari 1967 nog geen colleges en ik deed dat verzoek schriftelijk - toen nog de enige toelaatbare methode in professoraal

1 Zie Van Peursen 21959:475. De Christelijke Encyclopedie bespreekt amper personen, die bij verschijnen nog in leven waren. Zie ook Brümmer, 2000. 
Nederland. 1967-68 moest nog losbranden! Prompt kreeg ik een briefje terug met als toevoeging: "U kan telefonies bevestig." Van het Nederlands heeft Vincent zich - in tegenstelling tot Jean - nooit veel aangetrokken. Die maandagavond in januari 1967 werd een onvergetelijke avond. Ik belde om acht uur in Overvecht - dan de noordelijke nieuwbouwwijk van Utrecht aan. Datzelfde jaar zouden de Brümmers nog naar Bilthoven verhuizen: het beroemde adres Laurillardlaan 3. Professoren hadden toen in het algemeen niet veel tijd voor studenten - "zonde van de tijd". Om half tien dacht ik onrustig: "Ik moet nu wel aangeven, dat ik wil vertrekken". Om half elf had ik zelfs deze wellevendheid vergeten. Om twaalf uur nam ik schuldbewust afscheid. Al spoedig ontdekte ik, dat ik onder dat schuldgevoel niet gebukt hoefde te gaan. Reeds in november van dat unieke jaar werd ik voor 20 uur in de week studentassistent bij Prof. Brümmer en na mijn doctoraalexamen in september 1969 was ik op 1 oktober medewerker voor godsdienstwijsbegeerte. Dat was een bevoorrechte positie en ik kijk er met grote dankbaarheid op terug. Dat werk zou ik tot 1 september 1984 blijven doen. In 1981 ben ik bij Vincent gepromoveerd. Er zouden nog vele promoties volgen. Het was een fantastische tijd, maar in de zomer van 1984 was ik ervan overtuigd geraakt, dat ik voor het theologische onderwijs van de Hervormde Kerk - in systematische theologie en symboliek - moest gaan werken.

Prof. Brümmer was, toen hij aantrad, niet alleen de jongste hoogleraar in de theologische faculteit van Utrecht, hij was ook jongensachtig - en dat zou nog lang zo blijven. De jonge Prof. Brümmer deed bijna alles anders dan zijn oudere collega's dat deden en sommigen moesten daaraan wennen. Zo hield Vincent er niet van om alleen op stap te gaan en sleepte hij mij mee naar alle mogelijke vergaderingen, waar ik eigenlijk niets te zoeken had. Ik heb mijn ogen uit mijn hoofd gekeken en er zeer veel van opgestoken. Zo kwamen we eens Wim van Unnik tegen, die ons luidkeels groette: "Daar gaan de peripatetici." In tegenstelling tot de meeste collega's besteedde Vincent zeer veel aandacht aan zijn colleges en hij gaf ook glashelder college. Hij introduceerde tevens andere wijsgerige stof door ons vertrouwd te maken met de Engelse en Amerikaanse analytische wijsbegeerte. In plaats van de onbegrijpelijke Hegel en Heidegger bestudeerden we nu de glasheldere Hospers en Chisholm. Het wijsgerige onderwijs werd op een geheel andere leest geschoeid. Het is allemaal nog in Wijsgerige begripsanalyse na te proeven (Brümmer ${ }^{3}$ 1989). In de loop van de decennia daarna heeft Vincent Brümmer een zeer eigen oeuvre opgebouwd, maar de unieke kwaliteit van de wijsbegeerte in het theologische kandidaats en die van het godsdienstwijsgerige doctoraal waren voor zijn studenten en leerlingen het grootste en belangrijkste geschenk.

Het analytische project in de godsdienstwijsbegeerte heeft de laatste veertig jaar zeer veel opgeleverd. Dat geldt voor Nederland, waar Hubbeling en Brümmer het voortouw genomen hebben, en dat geldt ook internationaal, waar de New Essays in Philosophical Theology al veel effect gesorteerd had (Flew \& Maclntyre 1955). Daardoor is er veel nieuw inzicht in de aard van het christelijke geloof en van de christelijke theologie gegroeid, maar hoe zit het nu met de waarheid en de bewijsbaarheid van de waarheid van de christelijke theologie? Dat wens ik in deze bijdrage aan de orde te stellen.

\section{FIDES QUAERENS INTELLECTUM}

Geloof en theologie mogen zich niet opsluiten in eigen kapelletjes. Zij moeten uit hun schulp kruipen en het theologische perspectief naar buiten uitdragen. Dit houdt in, dat de theologie haar perspectief naar wijsbegeerte en wetenschap dient te verleggen. De ontgrenzing die de wetenschapsfilosofie kan bieden, opent de toegang naar een nieuwe wetenschappelijke stijl. Daarvoor moet men wel met de identiteit van de theologie vertrouwd zijn. Een onwetend christen is een hulpeloos christen. Een onwetende theoloog is een onmachtige theoloog, maar 
een onwetende wijsgeer is ook een onmachtige wijsgeer.

Wat is de hard core van de theologie, wijsbegeerte en wetenschap van het Westen? De godsleer is het stormcentrum, maar waarom was de godsleer het stormcentrum? Het christelijke godsbegrip wordt door de andere godsdiensten en de antieke philosophia uitgesloten, en als het christelijke geloof niet in staat is om met een eigen alternatief te komen, kan het hoogstens irrationele waarheid bereiken en irrationele waarheid is waarheid, waarvan men geen weet heeft. In de Latijnse Kerk leefde het geloof echter van een ander ideaal en een geheel andere ontdekking - Anselmus' ontdekking van fides quaerens intellectum. Het geloof kan echter alleen vruchtbaar en consistent doordacht worden, als de werkelijkheid geheel anders doordacht kan worden dan de antieke filosofie ons leert, maar de werkelijkheid kan alleen anders gedacht en bedacht worden, als men geheel anders leert te denken. Daarom staan we stil bij het historische draaipunt en laten we daarna de nieuwe geschiedenis die erom heen ligt, de revue passeren.

\section{Het historische draaipunt}

Het andere denken moest eerst uitgevonden worden. Het is in de scholastiek sinds de generaties van Lanfranc († 1089) en Anselmus († 1109) ontwikkeld: in de logica modernorum, die enkele eeuwen lang consistent wordt uitgebouwd. ${ }^{2}$ Cultuurhistorisch ligt de sleutel in het opmerkelijke feit, dat het Latijnse denken in de middeleeuwen een andere koers gaat varen dan het antieke denken en ontologisch ligt de sleutel in het opmerkelijke feit, dat een geheel nadere ontologie uitgevonden wordt: de contingentie-ontologie. Alle antieke filosofieën en alle religies in de archaïsche tijd en in de oudheid gaan uit van de vooronderstelling: alles is noodzakelijk en dan zijn ook alle standen van zaken noodzakelijk. Niet-noodzakelijke standen van zaken kunnen er niet zijn. Het christelijke denken van de middeleeuwen ontkent dit niet alleen, maar in het contingentie-denken krijgen ook vele woorden een andere betekenis, in de trant van wat Obbink Utrecht heeft ingeprent: "Wel dezelfde woorden, niet dezelfde waarden!" Zo komt dit denken ook met nieuwe begrippen voor noodzakelijkheid en contingentie.

Met de ontologie van de contingentie van de werkelijkheid is veel gemoeid. Als de antieke filosofie het bij het rechte eind gehad had, zou de christelijke geschiedenis van geloof en evangelie kansloos geweest zijn. Daarom lagen grote philosophoi als Plotinus en Porphyrius er ook niet wakker van. Omdat er veel mee gemoeid is, is het belangrijk te beseffen, dat de philosophia het bij het verkeerde eind gehad kan hebben. Het is belangrijk in te zien, waarom de antieke filosofie het niet bij het rechte eind had. Als het zo is dat in termen van de antieke filosofie de geschiedenis van Jezus onmogelijk is, sluit - omgekeerd - de werkelijke Jezusgeschiedenis de mogelijke waarheid van de antieke filosofie ook uit. Deze geschiedenis is historisch de spil, waarom alles draait. Het nieuwe Latijnse denken van de middeleeuwen wordt door haar opgeroepen.

\section{HISTORISCHE VERNIEUWINGEN}

De wetenschapsgeschiedenis moet tot de geschiedenis van de wijsbegeerte - inclusief die van de antieke filosofie - verbreed worden. Antiekfilosofisch denken stelt zich de verklaringsvraag niet aan het eigen adres. Het is kosmos-denken, dat diametraal tegengesteld is aan de moderne natuurkunde. Datzelfde geldt voor de relatie tot het christelijke geloof. De moderne natuurwetenschap heeft dit kosmosdenken niet uit zijn centrale rol getild. Dat staat op conto van de geschiedenis van het Evangelie. Wie de geschiedenis van theologie en wijsbegeerte uit de wetenschapsgeschiedenis wegdrukt, kan de ontwikkeling van de wetenschap niet begrijpen, want de wetenschapsgeschiedenis vestigt de blik op de universiteitsgeschiedenis. Daarmee

2 Zie Vos 1980 over De Rijk 1977. Zie ook Vos 2006a:558-65. 
komen de twaalfde en dertiende eeuw - de eerste eeuwen in de geschiedenis van de universiteit in de geschiedenis van het denken van de mensheid - binnen het gezichtsveld. We komen nu in scholastiek vaarwater.

De wetenschapsgeschiedenis staat niet op zichzelf. De gehele geschiedenis van onze cultuur bevestigt haar. De eigenlijke vraag is, wat voor wereld onze wereld zonder Pasen geweest zou zijn. Op het moment dat men beseft, dat de geschiedenis geen noodzakelijk verloop kent, doet zich de vraag voor, hoe we kunnen verklaren, wat er allemaal op contingente wijze gebeurd is. $\mathrm{Er}$ is de grote vraag: Waarom? Waarom zijn de ploeg en de molen uitgevonden, waarom de wetenschap en de zakdoek, de brug en de tunnel?

Om het geheim van de latere geschiedenis te kunnen begrijpen moet men zich in de statica van de oudheid verdiepen. Het christelijke geloof heeft veel van de ontwikkelingen tussen 300 v. Chr. en $400 \mathrm{n}$. Chr. kunnen profiteren, want wetenschappelijk en technologisch, filosofisch en theologisch heeft de antieke cultuur toen amper stappen vooruit kunnen doen. Niet alleen de godsdienstige, maar ook de culturele dynamiek moest bijna helemaal van het christendom komen. Dat geldt ook voor de middeleeuwen. De enorme rol die soms aan andere factoren wordt toegekend, komt niet uit de pen van geleerden, die iets van de middeleeuwse geschiedenis afweten.

De geschiedenis zou zonder Pasen eenvoudig gebleven zijn, want de statica van de oude wereld zou niet doorbroken zijn. De logica van de nieuwe ontdekkingen zou nooit uitgevonden zijn. De wind van de nieuwe uitvindingen zou nooit opgestoken zijn. ${ }^{3}$ Dan zou de boodschap nog steeds geweest zijn: Nooit iets nieuws. Nu werd het: Altijd iets nieuws, want de tijd is vervuld - door het Koninkrijk - en daardoor wordt een nieuwe geschiedenis geboren. In Jezus' leven ligt de geschiedenis open. De wereldgeschiedenis wordt Jezus-geschie-denis, want Hij is het, die geschiedenis maakt. Het oude gaat in Hem voorbij. Hij is het, die de geschiedenis heeft uitgevonden.

Er is veel rijkdom in de geschiedenis die door de geschiedenis van Jezus is opgeroepen. Door het christelijke geloof kwamen persoonlijke verantwoording en verantwoordelijkheid centraal te staan. De boodschap van bekering riep een kritische ethische positie op. Heiliging is een individuele zaak. Het archaïsche leven en het antieke denken kenden geen individualiteit, en ook geen heiliging (De Rijk 1980). Vernieuwingsbewegingen gaven keer op keer krachtige impulsen. Zonder Jezus zou het ook nooit tot een nieuw besef van zorg voor de ander gekomen zijn. Er zouden geen verzorgingstehuizen, centra voor ouden van dagen en ziekenhuisjes uitgevonden zijn, zoals christenen dat in de tweede helft van de vierde eeuw in Cappadocië en Klein-Armenië gedaan hebben. Medische zorg zou een fantoom gebleven zijn. Willibrord en Bonifatius zouden nooit geboren zijn en dus ook niet in de Lage landen verzeild geraakt zijn.

De strijd tegen de honger leidde in Frankrijk en de Nederlanden al vroeg tot nieuwe aanzetten in de landbouw, die in de loop van de twaalfde tot de vijftiende eeuw een nieuwe agrarische cultuur hebben opgeleverd. De ijzeren ploeg werd uitgevonden en het paard zette zijn schouders eronder. Vele monden konden nu worden gevoed. Godsdienstig revival en culturele dynamiek sloegen de klok. Tallozen sloten zich bij de monastieke vernieuwingsbewegingen aan. De antieke filosofie liet geen enkele ruimte voor het christelijke geloof, maar dat geloof schiep niet alleen in de middeleeuwse scholastiek een nieuw denken, maar kwam ook met nieuwe schooltypen, zodat bibliotheken opgebouwd konden worden en de strijd met het analfabetisme werd aangebonden, doordat men nu op grote schaal leerde lezen en schrijven. ${ }^{4}$

3 Zie AVos 2006b, en Vos 2008. Zie voor de bewijsbaarheid van centrale christelijke geloofsovertuigingen Vos 2006, de hoofdstukken 13-14 en 16.

4 Het middeleeuwse brongebied van de moderne natuurwetenschap wordt schitterend belicht doorGrant 1977, 2001 en 2009, Hannam 2010. 
Zonder deze Jezusgeschiedenis zou ons ook de techniek bespaard gebleven zijn. De molen en de schroef, de bril en het uurwerk verschijnen op het toneel. De natuur wordt geontmythiseerd en de arbeid bevrijd. Arbeid adelt is het nieuwe christelijke ideaal. Er wordt nu gewerkt, en er wordt nagedacht. De culturele dynamiek, die uit het christelijke geloof voortkwam, zou zonder dat geloof nooit ontketend zijn. Het zou bij de antieke statica gebleven zijn.

Het middeleeuwse denken ontdekte: analyseren, afleiden, argumenteren. De scholastiek is de grote vooronderstelling van het exacte denken. De universiteit wordt geboren en groeit en bloeit. Zonder de geschiedenis van het fides quaerens intellectum zou het nooit tot exacte wetenschap gekomen zijn. We zouden het zonder Copernicus en Galilei, zonder Huygens en Boerhave hebben moeten doen. Het zijn niet alleen christenen geweest, die talloze nieuwe uitvindingen op hun naam schreven - Galilei en Kepler, Beeckman en Huygens, Boyle en Newton -, maar het kwam ook nog eens juist uit hun geloof voort. Het beeld dat de westerse intellectueel van de geschiedenis van Europa heeft, ligt onder een dikke laag stof van onwetendheid en irrationaliteit bedolven. De westerse intelligentsia weet niet veel, ook al is het niet moeilijk om ons wetenschapshistorisch van al deze zaken op de hoogte te stellen. Door deze onwetendheid heeft men nog nooit van het echte Europa gehoord, omdat men geen idee van de geschiedenis van Europa heeft, want wie de geschiedenis van Europa niet kent, kent Europa niet.

Kortom, zonder Jezus Christus zouden we nog ongeveer leven als ten tijde van Jezus, per pedes apostolorum. We zouden ronddolen zonder wapens tegen kou en honger, ziekte en epidemieën. In de Lage Landen zouden we nooit verder dan hunebedden en moerassen, de wind en het water gekomen zijn. Duisternis en moerassen zouden ons nog steeds omringen.

\section{EEN AUCTORITATESCULTUUR}

Waarom is het niet eenvoudig het vernieuwde denken in de cruciale teksten uit de middeleeuwen op het spoor te komen? Het aspect dat voor ons cruciaal is, ligt in het feit dat men in een auctoritatescultuur geheel anders met teksten omgaat dan in een historische cultuur. Een auctoritatescultuur wordt allicht als een autoritaire cultuur geïnterpreteerd, maar dat komt, doordat men niet weet wat een auctoritas is en hoe zij functioneert. Het gaat er dus allereerst om meer inzicht te krijgen in wat een auctoritatescultuur is. ${ }^{5}$

De middeleeuwse cultuur was een auctoritatescultuur. Een auctoritas is geen autoriteit, maar een tekst: een gezaghebbende tekst. In de oudheid treffen we heilige boeken aan - overigens niet eens zoveel, maar wat er vooral toe doet, zijn de teksten die het onderwijsprogramma bevolken. Voor antiek en middel-eeuws besef hebben deze vaststaande teksten van het curriculum altijd gelijk. Ze functioneren als het ware als heilige boeken, maar welk gelijk bevatten ze?

Men was, ook al in de late oudheid, van oordeel dat een gezaghebbend auteur zijn gezag ontleende aan het feit dat men zakelijk op hem kon bouwen. De term auctoritas was bij de Romeinen van oorsprong een juridische term en verwees o.a. naar het schriftelijke bewijsstuk, dat borg stond voor een zakelijke (privaatrechtelijke) verhouding, omdat het deze konstitueerde. $\mathrm{Nu}$ is het merkwaardig dat men autor afleidde van authentes, dat de betekenis had van geloofwaardig, iets-echts-zeggend; de auteur (autor, auctor) was dus iemand wiens meningen of beslissingen, op grond van zijn [...] positie, gezaghebbend waren. ${ }^{6}$

Voor middeleeuws besef constitueert een intellectuele auctoritas geen waarheid: de Waarheid is onafhankelijk van de mens en een auctoritas constitueert haar niet, maar representeert haar:

"Hij (de autor) heeft het ware gezien en verwoord, en daarom is hij geloofwaardig en zou

men zakelijk gesproken dom doen door geen acht op hem te slaan (ibidem).

\footnotetext{
5 Met opzet gebruik ik het meervoud auctoritates om aan te geven dat het om iets anders gaat dan auctoritas, dat men ook met autoriteit kan vertalen.

6 De Rijk 1977:116.
} 
Een auctoritas is dus geen externe steunverlener, maar zelf een stuk rationele waarheid: auctoritas is niets anders dan een...

"...blootgelegde rationele waarheid (rationis aperta veritas), die ter wille van het nuttig

gebruik voor het nageslacht op schrift is gesteld."7

Wat kan men nu wel en wat niet, van zulk lezen van teksten verwachten? Het negatieve antwoord moet luiden, dat men er niet van verwachten mag, dat deze teksten historisch benaderd worden: we vinden er geen historische interpretatie van de auteurs uit het verleden, het gaat om een "pre-historisch" lezen: het historisch lezen is zich pas in het tweede kwart van de negentiende eeuw gaan ontwikkelen. Het positieve antwoord focust op het geïntendeerde waarheidsgehalte, dat men aan het licht brengt, en deze waarheid is de eigen waarheid, die de middeleeuwse auteurs in de vaststaande teksten vinden (De Rijk 1977:116-17). De auteurs lezen hun eigen waarheid - en hun eigen goedheid - in de teksten in (Vos 2006a:528-39).

De middeleeuwse cultuur was een auctoritates-cultuur. De traditionele visie ziet echter de auctoritas als een externe steunverlener waarop men zich beroept, zodat men niet zelf hoeft na te denken. Men plaatst de gezagsstructuur van zo'n cultuur tegenover de Verlichting, waarin men de onmondigheid achter zich zou laten. In Schoutens Grote sterrenkundigen wordt de traditionele visie helder verwoord:

"Nieuwe geestesstromingen hebben het werk van Copernicus voorbereid en mogelijk

gemaakt. Hierdoor werd veel autoriteitsgeloof ondermijnd en begon men te twijfelen aan

de dogma's van Aristoteles" (Schouten 1950:18).

Men ziet het middeleeuwse denken als een denken, dat bevangen gebleven is in de patronen van de antieke filosofie en in "de dogma's van Aristoteles" vastgeroest zat: men volgde slaafs de niet-christelijke oudheid en scholastiek is een vorm van aristotelisme. Oorspronkelijk was de wijsgerige mediëvistiek zelfs van mening, dat er in de middeleeuwen helemaal geen filosofie kon voorkomen, omdat geloof filosofische rationaliteit uitsluit, maar onder invloed van de katholieke neoscholastiek werd de protestantse visie vooral, dat middeleeuws denken aristotelisch is geweest (Vos 2006a: hoofdstuk 15).De traditionele visies zien echter de historische werkelijkheid over het hoofd. In wijsgerige en theologische teksten wordt weliswaar het Aristoteles dicit eindeloos herhaald, maar we moeten in deze teksten niet naar de historische Aristoteles vragen. We zouden vele middeleeuwse Aristotelessen kunnen onderscheiden: Alberts Aristoteles en Thomas' Aristoteles, de Aristoteles van Zeger van Brabant, Peckhams Aristoteles, Hendrik van Ghents Aristoteles, Godfreys en Duns' Aristoteles. Zelfs één auteur kan verschillende Aristotelessen hebben: Thomas' Aristoteles van het Scriptum, zijn Aristoteles van de Summa theologiae en de Aristoteles van zijn "commentaren"; Duns' Aristoteles van het exponere reverenter in zijn Sententiae "commentaren", in contrast met de Aristoteles van de directe confrontatie in Lectura I 8 and Ordinatio I 8, en de Aristoteles van zijn expositio en de Quaestiones super libros Metaphysicorum. Het zijn natuurlijk helemaal geen "Aristotelessen" zij weerkaatsen eenvoudig de vele manieren van het lezen van Aristoteles in een $a$-historischel auctoritates cultuur.

Het is nu verhelderend om te vragen, hoe John Duns Aristoteles' filosofie evalueert. De philosophi, die Aristoteles volgen, vertegenwoordigen het denken van vroeger dat niet christelijk was: de philosophia gaat ervan uit, dat de werkelijkheid noodzakelijk is, maar hoe ziet Duns zichzelf? Hij is een christen (catholicus) en een theoloog (theologus) en de theologia vertegenwoordig het denken van nu en van de toekomst: de werkelijkheid is contingent. Dat is precies het tegenovergestelde. Het gaat hier om een nieuwe wijsbegeerte en om een nieuwe theologie (Vos 2006a: hoofdstuk 14).

7 De Rijk 1977:116. "Authenticus" betekent dan "waarde en waarheid bevattend." Zie voor het universitaire arsenaal van gezaghebbende teksten omstreeks 1300 De Rijk 1977:117-24: "De gezaghebbende teksten". 
In deze cultuur treffen we een verborgen dynamiek aan. Zij wordt door een dynamiek gekenmerkt, die gewoonlijk over het hoofd wordt gezien, want zij verbergt zich in teksten die in hun oorspronkelijke betekenis geheel andere inhouden bevatten. De middeleeuwse auteurs vinden niet de waarheid van de oorspronkelijke auteur in zijn teksten, maar hun eigen waarheid. Zij lezen de auctoritates zoals zij de Bijbel lezen: als Fundgrube van waarheid. Wat de Bijbel betreft, exegetiseren zij niet. Zij zouden niet eens weten wat het woord "exegetiseren" betekent. Dat gaat niet alleen voor Thomas van Aquino en Duns Scotus op, maar ook voor Calvijn, Voetius en à Marck. Exegese is iets van de negentiende eeuw. In de middeleeuwse theologische en wijsgerige teksten vinden we dan ook precies het tegenovergestelde van wat het traditionele onderzoek erin vond: een christelijke herhaling van de antieke filosofie. We ontdekken er de fundamentele emancipatie van de denkpatronen van de antieke filosofie. Een nieuw denken wordt geboren: fides quaerens intellectum. De historische wijsbegeerte en theologie brengen ons dus met de wijsgerige traditie van het fides quaerens intellectum in aanraking. In dit licht ontdekken wij een andere doordenking van systematische vragen als: a) Is alles noodzakelijk? b) Bestaat God? c) Wat is de relatie tussen God en de Incarnatie?

\section{DE STELLINGNAME VAN DE ATHEOLOGIE}

In het onderzoek naar de a-theologie kunnen we verschillend te werk gaan. We kunnen bewijzen geven aan de hand van wat ons eigen denken verworven heeft, maar we kunnen ook werken met wat opponenten zelf naar voren brengen. A-theologen (filosofen die er aanspraak op maken te kunnen bewijzen, dat het atheïsme het bij het rechte eind heeft en dat God dus niet bestaat) bestrijden het christelijke geloof, maar het zijn ook noodzakelijkheidsdenkers. Hun visie houdt in:

"Als God niet bestaat, dan is de werkelijkheid noodzakelijk." Hieruit volgt krachtens modus tollens:

"Als de werkelijkheid niet noodzakelijk is, dan is het niet waar dat God niet bestaat." Hieruit volgt weer:

"Als de werkelijkheid contingent is, dan is het waar dat God bestaat. ${ }^{8}$

Is de werkelijkheid contingent? Is het noodzakelijkheidsdenken te weerleggen? Kunnen we aantonen, dat de werkelijkheid contingent is? Als we zo'n bewijs kunnen overleggen, tonen we vervolgens met behulp van modus ponens aan, dat God bestaat. Daarbij gaan we dan niet van het eigen standpunt uit, maar van de stellingname van de oppositie, die zich bij de grondpositie van de antieke filosofie aansluit: Alles is noodzakelijk. In plaats van de antieke filosofie historisch te benaderen kan men haar ook logisch beschouwen door te opperen, dat haar grondslag onwaar zou kunnen zijn. Wie waren nu van mening, dat de aristotelische metafysica niet onwaar kan zijn? In elk geval was Aristoteles zelf dat van mening - met de antieke aristotelianen -, de grote islamitische filosofen zoals Avicenna en Averroës, en ook de neothomistische neoscholastiek was die optie toegedaan. Aan het neothomisme is al te zien, hoe ver modern katholiek denken van het middeleeuwse denken kan afstaan. Theologisch is dit ook belangrijk, omdat veel protestantse theologie in de moderne tijd zich hierbij heeft aangesloten.

Wij nemen nu echter aan, dat het niet zo is, dat Aristoteles onomstotelijk gelijk heeft. Als we aannemen, dat het mogelijk is, dat iets onwaar is, verwerpen we dat het onmogelijk is dat het niet waar is. Zo'n verwerping hoeft ons niet te bevreemden. Wie zo niet te werk gaat, kan nooit iets kritisch aan de orde stellen. We zetten de eerste stap: we opperen de hypothese, dat het mogelijk is, dat Aristoteles het niet bij het rechte eind heeft:

"Het is mogelijk, dat Alles is noodzakelijk niet waar is."

8 Immers is $p$ noodzakelijk of niet-noodzakelijk en als $p$ niet noodzakelijk is, is $p$ contingent, en de dubbele ontkenning mogen we elimineren. 
Het is dan mogelijk, dat niet alles noodzakelijk is, en dat er feiten en proposities zijn, die niet noodzakelijk zijn. De waarheid van $2+2=4$ is noodzakelijk en de niet-noodzakelijkheid van een propositie moet dus anders van aard zijn dan de status van $2+2=4$ of "Als Socrates rent, dan loopt hij."

Zulke voorbeelden vormen de proposities Socrates loopt en Socrates rent zelf, want als "Als Socrates rent, dan loopt hij." noodzakelijk is en de proposities Socrates rent en Socrates loopt logisch anders van aard zijn dan Als Socrates rent, dan loopt hij, zijn ze dus niet noodzakelijk. Dan zijn ze contingent (= niet-noodzakelijk).

Deze argumentatie stoelt alleen op de basislogica en haar modale uitbreiding en basislogica wordt aan alle universiteiten van de wereld onderwezen. Wat we voor Socrates loopt hebben laten zien, geldt ook voor vergelijkbare proposities als Irma studeert theologie en Imre studeert wijsbegeerte. Als Socrates rent niet noodzakelijk is, geldt hetzelfde voor alle standen van zaken die van de geschiedenis deel kunnen uitmaken. Het noodzakelijkheidsdenken heeft geen gelijk: de geschiedenis is contingent. Als contingentie zelf noodzakelijk is, heeft Aristoteles het helemaal verloren, want als contingentie zelf noodzakelijk is, is zij niet uit schakelen. Dan zit men aan de contingentie vast en zit men ook aan de contingentie van de werkelijkheid vast. Daar helpt geen atheïstisch lieve moederen meer aan. Wat noodzakelijk is, is niet niet-noodzakelijk te maken en daarmee is het onaantastbaar.

"De contingentie van de geschiedenis is zelf noodzakelijk" en de noodzakelijkheid van de werkelijkheid ook niet door Aristoteles en zijn bondgenoten te redden. Wat niet uit te schakelen is, is ook niet door Plato en Aristoteles, Hegel en Marx, Richard Dawkins en Herman Philipse en hun bondgenoten te elimineren.

De werkelijkheid is contingent en haar geschiedenis is contingent en samen met de waarheid van "Als de werkelijkheid contingent is, dan is het waar dat God bestaat" hebben we reeds geconcludeerd: "God bestaat."

Als de geschiedenis contingent is, zijn alle gebeurtenissen van de wereld contingent, want de wereld is de totaalverzameling van alle gebeurtenissen, maar als de wereld contingent is, kan zij zichzelf niet verantwoorden. Zij kan niet in zichzelf rusten. lets wat op contingente wijze waar is en contingent is, moet contingent gedaan zijn en daarom moet het ook contingent gewild zijn. We hebben echter gezien dat de $a$-theologie zelf oplevert: God bestaat. Er is dus iemand, die haar gewild heeft. Wie uitvoert, wat Hij als wereld wil, is de Schepper en alleen God kan de Schepper zijn. Ergo: God bestaat als Schepper en de Schepper bestaat!

\section{De incarnatie}

Er valt nog meer te zeggen. Jezus Christus is het Licht op de berg. Zijn diepe ontferming is zo origineel, dat het antieke daglicht haar niet kon verdragen. Zij is zo fundamenteel, dat de wereld zonder zijn barmhartigheid en misericordia een hel gebleven zou zijn. Zijn culturele revolutie raakte voelen en willen, denken en doen. Zij schiep een andere zede en een andere rede.

God kan alleen maximaal goed zijn - dat is de clou van Anselmus' Proslogion - maar wie maximaal goed is, handelt ook optimaal goed in wat Hij doet. Wie zo handelt, laat niet varen het werk van zijn handen - dat is de clou van Anselmus' Cur Deus homo? Dus: gegeven dat onze werkelijkheid is zoals zij is, mag zij zich in een incarnatie in de geschiedenis verheugen, waarin God zo goed mogelijk handelt en Hij handelt zo goed mogelijk door zelf te komen.

Onze geschiedenis mag zich in Gods zorg verheugen en in een incarnatie, waardoor God zo goed mogelijk handelt. Hij handelt zo goed mogelijk door zelf te komen. Er is maar één geschiedenis, die hiervoor kandidaat kan staan. Dat is de geschiedenis, die de grondslag van het archaïsche en antieke leven en denken gekraakt heeft. Wie het daarmee eens is, kan hem niet kraken, want die wil hem niet kraken. Daarin speelt de wil ook helemaal geen rol, want alles 
staat er in het teken van de noodzakelijkheid - in een wereld, die in statica en noodzakelijkheid zit vastgeklemd. ${ }^{9}$ Daardoor valt er niets te willen. Daar viel niets te willen, maar toen kwam Hij die zei: Ik wil!

Het is ook de enige geschiedenis, die deze grondslag gekraakt heeft. Deze geschiedenis is dus de enige kandidaat en zij is de geschiedenis van lemand. Wij weten, hoe deze kandidaat heet en wie deze kandidaat is. Het was Eén tegen allen, maar Hij overwon:

Mijn Heer en mijn God!

Rabbouni! Jezus, de Heer, de Opgestane! Ook zo is de wereldgeschiedenis met de geschiedenis van Jezus verbonden en zo blijkt, dat de Opgestane de Heer is. De moderne kritiek ziet de werkelijke "evidence" over het hoofd. Zij neemt het historische denken ook niet ernstig, maar omdat de Opgestane de geschiedenis serieus neemt, schiep Hij zelf een weelde aan "evidence." Die "evidence" heeft een overduidelijke boodschap:

Rabbouni! En: Mijn Heer en mijn God!

Rabbouni! Jezus, de Heer, de Opgestane!

\section{Het Koninkrijk van God incarnate}

Omdat wat doorslaggevend is, op Jezus' woorden en daden gegrondvest is, moeten we ons ook geheel naar Zijn wil richten! Dat verdient Hij! De zaak van het christelijke geloof is ijzersterk, maar toch is wat christenen verdedigen, vaak onhoudbaar. Het is dan ook zaak om ons ootmoedig en nederig tot Hem te wenden, de Rots van ons behoud. We moeten ontdekken, dat het christendom een berouwgodsdienst is (Vos 2001). We mogen ook de klassiek christelijke theologie van de $A A$ lijn herontdekken als de adequate vertolking van het christendom als berouwgodsdienst.

De geschiedenis zelf schuift God incarnate naar voren. Op het vlak van het denken zien we, dat de fides quaerens intellectum zich van de antieke filosofie emancipeert. De geschiedenis van de wetenschap laat zien, dat haar perspectief erom vraagt, dat een nieuw denken en een nieuwe wijsbegeerte nodig zijn. Ook de geschiedenis van de moderne wetenschap maakt duidelijk, dat zij niet zonder Jezus' geschiedenis van de grond kon komen. De geschiedenis van de gehele wetenschap legt de nodige gebieden bloot en verbreedt het perspectief naar het geheel van de werkelijkheid. Daarin speelden christelijk geloof en theologie de hoofdrol. Het wetenschappelijke perspectief moet het christelijke perspectief omhelzen. Het christelijke perspectief omhelst het wetenschappelijke.

\section{BIBLIOGRAFIE}

Brümmer, Vincent ${ }^{3} 1989$, Wijsgerige begripsanalyse: Een inleiding voor theologen en andere belangstellenden. Kampen: Kok.

Brümmer, Vincent 2000. “Arnoldus Ewout Loen," Biografisch Lexicon voor de Geschiedenis van het Nederlandse Protestantisme V. Kampen: Kok, 348-51.

De Rijk, L.M. 1977. Middeleeuwse wijsbegeerte. Traditie en vernieuwing, Assen 1977

De Rijk, L. M. 1980. Het ongure individu, Leiden: RUU.

Flew, Antony en Alasdair MacIntyre (red.) ${ }^{1} 1955$, New Essays in Philosophical Theology, Londen: Macmillan. Grant, Edward 1977. Physical Science in the Middle Ages, Cambridge: CUP.

Grant, Edward 2001. God and Reason in the Middle Ages, Cambridge: CUP.

Grant, Edward 2009. A History of Natural Philosophy: From the ancient world to the nineteenth century, Cambridge/New York: CUP.

Hannam, James 2010. Gods filosofen: Hoe in de Middeleeuwen de basis werd gelegd voor de moderne wetenschap, Amsterdam: Nieuw Amsterdam.

Schouten, W. J. A. 1950. Grote sterrenkundigen, Rijswijk: Leidsche Uitgeversmaatschappij.

Van Peursen C.A. ${ }^{2} 1959$, “Arnoldus Ewout Loen”, Christelijke Encyclopedie IV, Kampen: Kok, 475.

9 Zie $\$ 2$. 
Vos, Antonie 1980. “Middeleeuwse Wijsbegeerte. Traditie en vernieuwing," Nederlands Theologisch Tijdschrift 34, 66-72.

Vos, Antonie 2001. "Ligt Europa in Holland?," Kontekstueel 15.4 (2001) 26-35.

Vos, Antonie 2006a. The Philosophy of John Duns Scotus, Edinburgh: Edinburgh University Press, 2006

Vos, Antonie 2006b. "Over christelijk geloof en Europa". Kerk en Theologie 57, 292-314.

Vos, Antonie 2008. "Geloof als het geheim van de geschiedenis", Kontekstueel 22.4, 11-14

\section{KEY WORDS}

Religion

Faith

Historical theology

Systematic theology

Philosophy of religion 